\title{
Advances in the application of biomimetic surface engineering in the oil and gas industry
}

\author{
Yanbao GUO ${ }^{1,2, *}$, Zheng ZHANG $^{1}$, Siwei ZHANG ${ }^{1, *}$ \\ ${ }^{1}$ College of Mechanical and Transportation Engineering, China University of Petroleum, Beijing 102249, China \\ ${ }^{2}$ State Key Laboratory of Petroleum Resources and Prospecting, Beijing 102249, China \\ Received: 30 October 2018 / Revised: 02 February 2019 / Accepted: 31 March 2019 \\ (C) The author(s) 2019.
}

\begin{abstract}
Friction is widespread in almost every field in the oil and gas industry, and it is accompanied by huge energy losses and potential safety hazards. To deal with a series of questions in this regard, biomimetic surfaces have been developed over the past decades to significantly reduce economic losses. Presently, biomimetic surface engineering on different scales has been successfully introduced into related fields of the oil and gas industry, such as drill bits and the inner surfaces of pipes. In this review, we focused on the most recent and promising efforts reported toward the application of a biomimetic surface in oil and gas fields, indicating the necessity and importance of establishing this disciplinary study. Regarding the oil and gas industry, we mainly analyzed and summarized some important research results into the following three aspects: (i) applications in reducing the wear of exploration production equipment and its components, (ii) separation and drag release technologies in oil/gas storage and transportation, and (iii) functional coatings used in oil and gas development in oceans and polar regions. Finally, based on an in-depth analysis of the development of biomimetic surface engineering in the fields of oil and gas, some conclusions and perspectives are also discussed. It is expected that biomimetic surface engineering can be used in oil and gas fields more widely and systematically, providing important contributions to green development in the near future.
\end{abstract}

Keywords: friction and wear; biomimetic surface engineering; oil and gas industry

\section{Introduction}

The direction of biological evolution is a result of the natural selection of the environment. Organisms have evolved over millions of years, creating their own unique structures and functions. In addition, the process of humans learning from nature is also gradually transforming from unconsciousness to consciousness. Friction widely exists in the oil and gas fields, including the internal parts of the oil field equipment and the external working environment. Furthermore, large amounts of wear, corrosion, and energy consumption also pose a significant resistance to sustainable development. The field of bionics is a combination of both biological sciences and technical sciences, whereas biomimetic tribology is an intersection of two disciplines, tribology, and bionics [1]. To date, the application of bio-tribology, which plays a significant role in all aspects of industry, has already achieved some progress in drilling, pipe transportation, and other fields (see Table 1). Giving full play to the advantages of biomimetic tribology, the development of modern tribology theory is expected to be promoted. This can not only break through the related technical problems, it can also have an important impact on innovation and the development of the oil and gas industry, and it is also beneficial for the green development of energy conservation and a reduction of emissions.

* Corresponding authors: Yanbao GUO, E-mail: gyb@cup.edu.cn; Siwei ZHANG, E-mail: swzhang99@sina.com 
Table 1 Application of biomimetic surface engineering in oil and gas fields.

\begin{tabular}{|c|c|c|c|c|}
\hline Areas & Applications & Effects & References & Treatment methods \\
\hline \multirow{5}{*}{$\begin{array}{l}\text { Underground } \\
\text { technology }\end{array}$} & Drilling tool & & & \multirow{7}{*}{$\begin{array}{l}\text { Macro-scale } \\
\text { machining } \\
\text { (laser engraving } \\
\text { additive, etc.) }\end{array}$} \\
\hline & Bits & & {$[2-4]$} & \\
\hline & Pipe joints & Improve wear resistance/service life & {$[5]$} & \\
\hline & Expansion cones & & {$[6]$} & \\
\hline & Drilling fluid & Reinforce the well wall & {$[7-9]$} & \\
\hline \multirow{2}{*}{$\begin{array}{l}\text { Ground } \\
\text { equipment }\end{array}$} & Piston/gear & Reduce wear/increase lubrication & {$[10-14]$} & \\
\hline & Brake & Improve wear resistance/heat dissipation & {$[15,16]$} & \\
\hline \multirow{2}{*}{ Transportation } & Pipeline & Drag release & {$[17-19]$} & \multirow{6}{*}{$\begin{array}{l}\text { Micro-scale } \\
\text { coatings/films } \\
\text { (physics } \\
\text { chemistry, etc.) }\end{array}$} \\
\hline & Oil-water separation & Improve efficiency & {$[20-22]$} & \\
\hline \multirow{4}{*}{$\begin{array}{l}\text { Ocean/polar } \\
\text { platform }\end{array}$} & \multirow{2}{*}{ Platform } & Anti-corrosion & {$[23-26]$} & \\
\hline & & Anti-icing & {$[26-28]$} & \\
\hline & Ship & Drag release/anti-fouling & {$[29-32]$} & \\
\hline & Oil spills cleaning & Collect oil & {$[33,34]$} & \\
\hline
\end{tabular}

\section{Application in drilling and production}

When most oil/gas exploration equipment is in operation, its working contact surface is under extreme conditions, including a heavy load and high intensity, for extremely long periods of time. However, with the deepening research into biomimetic tribology and its application, significant progress has been made in improving the performance of equipment components (mainly wear resistance) in recent years, which has provided a new method to prolong the service life of the equipment and enhance its reliability with an improvement in system safety [35]. Biomimetic surface engineering is mainly used in the drilling process through surface treatment technology applied to strengthen the service performance of the contact surface of the equipment under harsh working conditions. Moreover, owing to the application of biomimetic surface engineering, various results have been achieved in oil/gas exploration equipment (i.e., bits, drilling tools, and pistons).

\subsection{Bionic bits}

The bit performance is critical to the mechanical drilling rate and service life. Presently, polycrystalline diamond compact (PDC) bits are widely used owing to their excellent cutting performance and service life. However, numerous studies have revealed the disadvantages of conventional PDC drill bits, such as an insufficient bonding force between the diamond and cemented carbide, an unobvious anti-sticking effect, and rapid wear [36]. Thus, Jilin University in China has developed new types of drill bits from a bionics perspective. For instance, Ren's research team has committed to improving the comprehensive performance of bionic bits, such as the cutting force, anti-adhesion, and wear resistance. They have already carried out in-depth research into the design of bionic drill bits [2, 4], the rock fragmentation mechanism [3], the wear behavior and mechanism under different scales [37, 38], the coating materials [39], and the anti-erosion performance of a bionic unit coating [40]. For example, in the design of a bionic claw toe diamond inlay design, the front paws of a pangolin have been referenced. As a result, the drilling speed and service life have been significantly improved. The experiment results show that the average drilling speed can be increased by $20 \%$, and the operating life can be more than doubled when applying the same drilling speed. A bionic coupling PDC drill bit uses the distribution of cellulose and lignin found in bamboo as a reference, coupling the design according to the non-smooth shape of the shell surface, and other biological characteristics, as shown in Fig. 1. In addition, the field test results showed that the drilling speed can be increased by 1.5-fold when compared with ordinary PDC bits, 


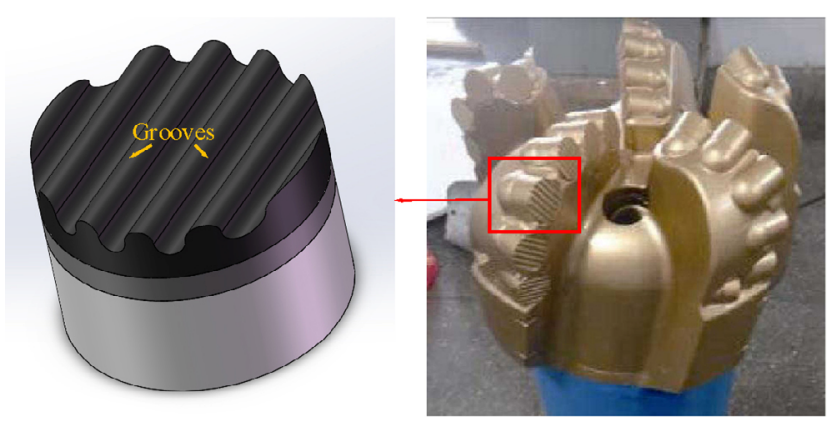

Fig. 1 Bionic coupling PDC bit.

greatly shortening the construction period [36].

\subsection{Biomimetic drilling fluid}

Wellborn stability is a problem that has long plagued drilling both at home and abroad. It is worth noting that horizontal wellbore instability is a more serious problem than vertical wellbore instability [41]. To deal with this issue, Xuan et al. [7] designed a biomimetic drilling fluid system by imitating the super adhesion ability of marine mussel protein that can spontaneously solidify on the surface of the wellbore rock, forming a dense and adhesive biomimetic shell, thereby maintaining the stability of the wellbore wall. Additionally, the biomimetic inhibitor has a good ability to inhibit the expansion, dispersion, and exfoliation of shale hydration, as well as effectively suppress the slurry production [42]. In addition, Zheng et al. [8] developed a biomimetic velvet pouch drilling fluid that mimics the structure of bacteria. It can temporarily stop the loss of a reservoir without a solid phase during the drilling process. Recently, biomimetic velvet pouch drilling fluid has played an important role in coal bed methane (CBM) underbalanced drilling, air drilling, leak-proof plugging, and rapid drilling. Furthermore, the performance of a mud shale biomimetic treatment liquid has shown that it can effectively reduce the surface energy of the shale surface, transforming the surface from hydrophilic to hydrophobic, preventing the mud shale from being self-absorbent, enhancing the strength of the shale in an aqueous solution, and thus maintaining the stability of the mud shale well wall. At the same time, the hydrophobic surface formed by biomimetic treatment liquid has displayed a certain wear resistance, an anti-salt characteristic, alkali resistance, and thermal stability.

\subsection{Biomimetic drilling tools}

A drill pipe is the core tool used in the process of geological drilling and oil extraction, connecting the ground and underground. During the drilling process, the tool joints apply a complicated force and the working environment is consistently harsh, making it easier to damage the drilling tools. Therefore, the wear resistance of the tool joints directly affects the service life. Furthermore, biomimetic surfaces have been optimized using a wear-resistance belt and threaded shoulder of the tool joint. Through a simulation analysis, it was concluded that the addition of a biomimetic surface is better than an untreated surface with the effects of a tensile force, bearing bending moment, and wear resistance of the tool joints. Gao et al. [5] also proposed the fabrication of non-smooth structures on the surface of the tool joints artificially to produce non-smooth wear characteristics, which can increase the service life of the drill pipe and greatly reduce the cost of the drilling. Figure 2 shows a biomimetic non-smooth surface expansion cone [6]. Moreover, during an expansion tube operation, the non-smooth surface reduces the frictional resistance between the expansion cone and the inner wall of the expansion tube, thereby improving the wear resistance of the expansion cone.

\subsection{Biomimetic pistons}

According to statistics, the energy consumption of a piston cylinder liner of a diesel generator set by the drilling rig accounts for approximately $50 \%$ of the friction loss of the entire diesel engine [43]. Again, the contact friction between the piston skirt and the cylinder sleeve, the poor heat dissipation, and the
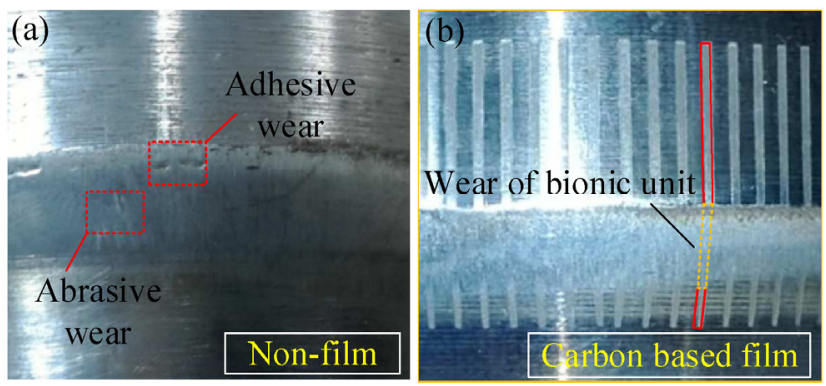

Fig. 2 Worn surface of expansion cone: (a) original and (b) biomimetic surfaces. Reproduced with permission from Ref. [6], (C) Trans Tech Publications 2014. 
high-temperature corrosion can make the piston extremely vulnerable to fatigue failure [44]. Wu and $\mathrm{Xi}$ [45] have conducted numerous studies and tests on the biomimetic piston used in an internal combustion engine. Based on the characteristics of the body surface of shellfish, they processed an optimized surface on the piston skirt of a piston-cylinder. In addition, their test results showed that a biomimetic piston is superior to an ordinary piston in terms of heat dissipation, friction reduction, and lubrication performance. Sun et al. [46] designed and manufactured concave-shaped bionic components on the surface of a mud pump piston. Under the same test conditions, it was found that the biomimetic mud pump piston significantly increases the service life by 2.19 -fold. Interestingly, different biomimetic structures have also shown different improvements in their service life and dynamic seal capabilities. For example, the wear life of a bionic pitshaped piston is better than that of a striped piston.

\subsection{Biomimetic brake blocks used in drilling draw works}

To improve the wear resistance and service life of gray cast iron brake discs for drilling draw works, Song et al. [47] applied the bionic coupling principle to the processing of non-smooth units such as dots, stripes, and grids on the surface of gray cast iron using a laser processing. Likewise, the friction and wear properties of different bionic units were investigated. The test results showed that a bionic coupling brake disc has a high friction coefficient and good wear resistance, and the service life is increased by more than $50 \%$. Considering that the braking torque of a rig brake is much larger than that of an automobile, the braking effect, service life, and economic value require more support both theoretically and experimentally. Biomimetic brake blocks applied to drilling draw works may be a good prospect.

In conclusion, the synergistic mechanisms of a biomimetic surface during the application of drilling and production equipment can be summarized as follows. The bionic units on the surface produce a self-lubricating effect by storing abrasive debris or a lubricating fluid. In addition, the non-smooth surface blocks the continuity of the liquid layer on the surface, achieving a desorption effect. The expansion of the surface area improves the heat dissipation efficiency, and the biomimetic surface relies on a localized contact to achieve a uniform stress distribution. In short, during the process of oil and gas drilling and exploration, even when the operation condition of the oil equipment is extremely poor, the biomimetic surface at the macro-scale can exploit to the advantages of the wear resistance and drag reduction, and an unprecedented development in this field has been achieved. Although research into new materials is still important, the standardization and systematization of a biomimetic surface design and its application are critical to the subsequent development.

\section{Application in oil/gas storage and transportation}

Over the past few years, a biomimetic superhydrophobic surface has been extensively explored as a special state of surface infiltration, and this discovery has accelerated the research into the phenomenon of super-wetting found in nature. As a result, different types of super-soaking phenomena have been continuously developed and researched [48]. Thus far, super-infiltration systems have been formed, and the application of super-infiltration surfaces has also been gradually developed, as shown in Fig. 3. The composition and roughness of the surface are the two main factors influencing the surface performance. In general, there are two ways to prepare a superhydrophobic surface: one is the use of new low-surface-

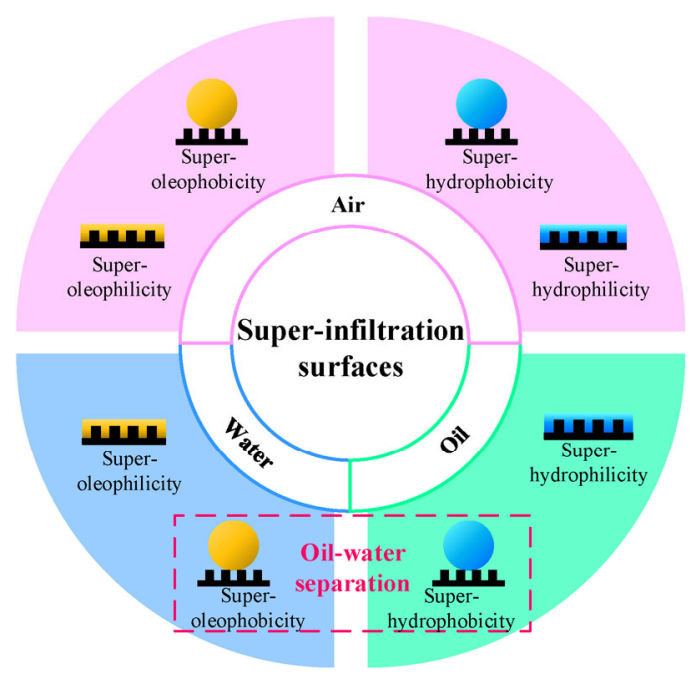

Fig. 3 Different models of super-infiltration surfaces. 
energy materials with a rough surface, namely, hydrophilic materials, and the other is to modify existing low-surface-energy materials. Some common methods for fabricating superhydrophobic surfaces are briefly summarized in Table 2. Compared with the harsh friction contact that occurs during the drilling process, the working conditions in oil/gas storage and transportation are relatively mild, and thus more focus has been given to the functionality of a biomimetic surface. Table 2 summarizes the following aspects mentioned herein, including oil and water separation technology, pipeline resistance reduction, and corrosion protection technology.

\subsection{Oil-water separation}

With the exploitation of an oil field, the amount of water in some well fluids exceeds $95 \%$. Therefore, higher requirements have been imposed on oil-water separation technologies. Oil-water separation can be divided into the processes of extracting oil from an oil and water mixture, and removing oil and other impurities from the oily wastewater [49]. Presently, oil-water separation systems are commonly used in the industry (particularly in offshore platforms). Nevertheless, for an improvement in oil-water separation technologies, as described below, many challenging issues still exist, such as a low separation efficiency, heavy oil extraction, down hole separation, and deep-water operation. Because membrane separation technology has the advantages of a low energy consumption, simple processing, less pollution, and strong versatility, the adoption of functional membranes instead of traditional separation membranes will be a future development trend. However, a super ultra filtration membrane is still at the laboratory research and development stage. Tao et al. [50] prepared a super-amphiphilic poly(vinylidene fluoride) (PVDF) membrane that achieves a switchable transport performance, and the membrane displays a superior permeability as well as a high separation efficiency. They also fabricated a stable super-hydrophilic surface by inlaying $\mathrm{TiO}_{2}$ nanoparticles on a polylactide (PLA) ultra filtration membrane [51]. Meanwhile, the idea of using functional nanoparticles to construct a highstrength polymer membrane has been described. Subsequently, a novel and effective coated mesh for oil-water separation was fabricated, as shown in Fig. 4 [52]. Zhang et al. are committed to the development of oil-water separation membranes, including amphiphilic poly(ether sulfone) membranes [53, 54] and gelatinbased aerogel [55]. In addition, a stimulus response membrane [56-59], an inorganic nanostructure superhydrophobic mesh membrane [60, 61], and a molecular brush structure super-hydrophilic membrane

Table 2 Summary of common fabrication methods of superhydrophobic surfaces.

\begin{tabular}{|c|c|c|}
\hline Materials & & Methods (advantages \& disadvantages) \\
\hline \multirow[t]{4}{*}{$\begin{array}{l}\text { Organic } \\
\text { substance }\end{array}$} & Etching & $\begin{array}{c}\text { Widely used but some organics need to further reduce surface energy for the } \\
\text { hydrophobic groups are destroyed }\end{array}$ \\
\hline & Electrostatic spraying & $\begin{array}{c}\text { Simple and applicable to many areas, the doping of nanoparticles or fibers effectively } \\
\text { increases the hydrophobicity }\end{array}$ \\
\hline & Phase separation & Easy to production, but difficult to control \\
\hline & Templating & $\begin{array}{l}\text { Can be produced quickly and at low cost, but the preparation of large surfaces is } \\
\text { too complicated }\end{array}$ \\
\hline \multirow[t]{5}{*}{$\begin{array}{l}\text { Inorganic } \\
\text { substance }\end{array}$} & Sol-gel & $\begin{array}{c}\text { Can form transparent superhydrophobic surfaces and easily tuned, but poor } \\
\text { controllability }\end{array}$ \\
\hline & Self-assembly & Convenient and easy to product, but its durability is poor \\
\hline & Etching & Widely used in surface processing \\
\hline & Layer-by-layer & Can fabricate kinds of surface morphology, but time-consuming \\
\hline & Electrochemical & Easy to control, process is safe but energy costs more \\
\hline \multirow[t]{3}{*}{ Metal } & Corrosion & Processing is convenient and easy, but may need follow-up process \\
\hline & Machining & Hard to form surface morphology once and requires other processing \\
\hline & Thin-film & Can be applied in many ways \\
\hline
\end{tabular}



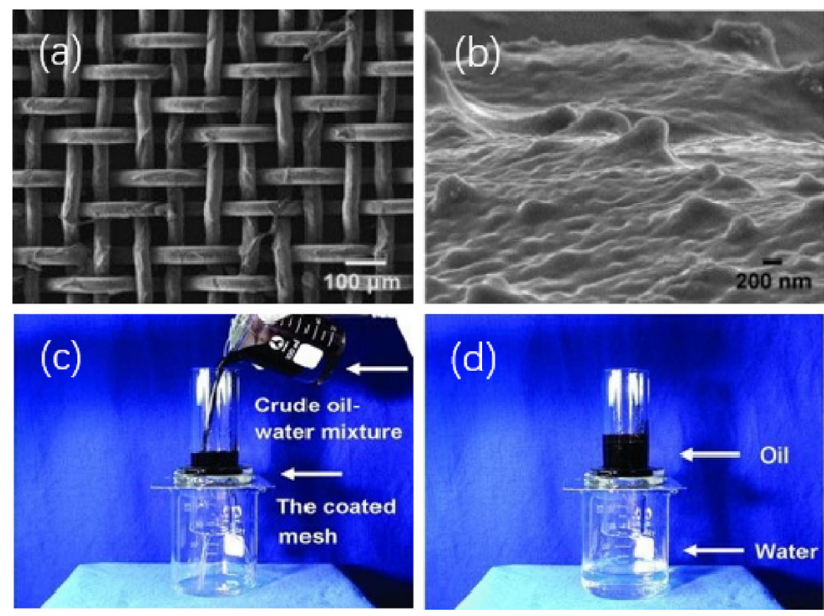

Fig. 4 Superoleophobic hydrogel-coated mesh for oil-water separation. (a) and (b): SEM images of PAM hydrogel-coated mesh, (c) and (d): process used in crude oil and water mixtures with hydrogel-coated mesh. Reproduced with permission from Ref. [52], (c) Wiley 2011.

[62] have also led to the intelligent development of membrane technologies. However, to better transition from the experimental stage to the industrial application stage, the relationship between the separation flux efficiency [63], preparation cost [64], and service life [65], as well as the related evaluation methods and criteria, need to be studied further.

\subsection{Oil/gas pipeline transportation}

Over the past few years, drag reduction technologies used in pipelines in the long-distance transportation field have become the focus of active concern and exploration in related industries. If a biomimetic surface technology with a drag reduction can be applied to the inner layer of the oil transmission pipeline, the frequency of pigging that occurs in a closed pipe may be significantly reduced, and the material can also effectively reduce the fluid resistance, lowering the energy consumption of the pipeline.

From the perspective of hydromechanics, most of the energy available in pipeline transportation is consumed owing to the frictional resistance with the inner wall, but the prospect of reducing the friction coefficient by reducing the roughness of the inner wall has been relatively low [66]. In this regard, biomimetic surface engineering has been well applied. For instance, a pipeline with a diameter of $6 \mathrm{~mm}$ and a wall thickness of $12 \mathrm{~mm}$ coated with a super-hydrophobic material achieves a drag reduction of $14 \%$ [67]. Choi et al. [68] applied a super-hydrophobic nanostructure surface to a pipeline and found that the pressure in the pipeline was reduced by $20 \%-30 \%$. In addition, a super-hydrophobic surface composed of secondary micro/nanostructures achieves a better drag reduction effect than a primary structure surface. The drag reduction effect of a novel inner coating of a pipeline has been validated experimentally using air/gas, and the results showed that the drag release efficiency can achieve a spectacular $8 \%$ increase compared with the original coated pipe as a control, as shown in Fig. 5. In a follow-up study, it was found that the parallel stretched surface improves the drag reduction performance to a small extent, and a perpendicular stretched surface expands the selection range of the flow rate as compared with the original biomimetic surface [69].

Although the micro/nanostructures of a biomimetic surface can achieve a good drag reduction effect, a proper understanding of the drag reduction mechanism has yet to be achieved. Several different explanations for the mechanism of a drag reduction have been proposed:

A secondary vortex. The interaction between the groove tip and the fluid creates a secondary vortex

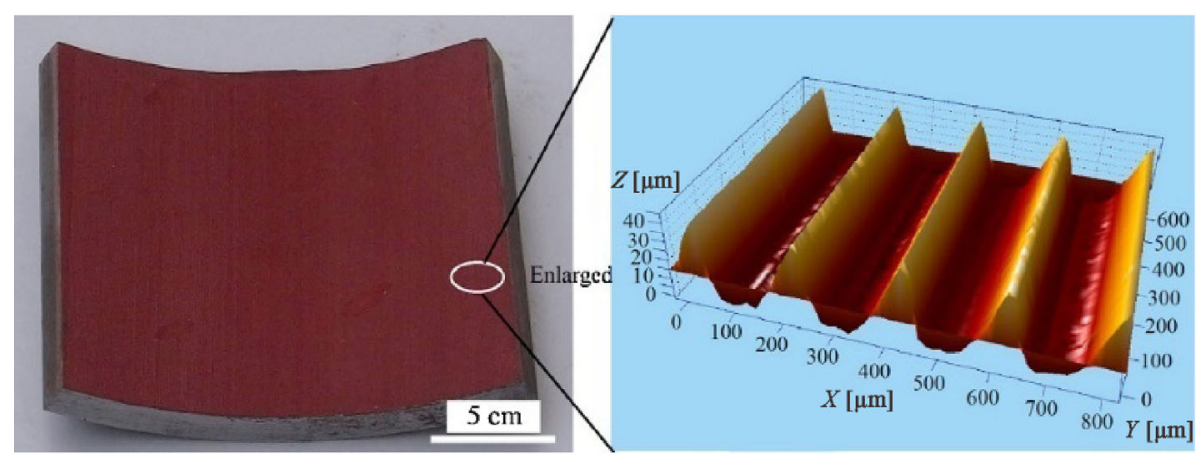

Fig. 5 Inner coating of pipe and enlarged micro-morphology. Reproduced with permission from Ref. [70], (C) Elsevier 2015. 
that rotates in the opposite direction of the radial vortex, impedes the formation of transverse corrugations perpendicular to the direction of the fluid flow, and successively reduces the lateral momentum exchange of the fluid from the perspectives of theory and experiment.

A block lateral vortex. A radial vortex is in contact with the tip of the groove during an undershoot movement, and thus the transverse expansion of the vortex can be blocked by the groove structure, limiting its radial expansion and reducing the momentum in the turbulent boundary layer.

The scales of the structures. The scales are mostly sand form a whole. The semi-enclosed space under a scale is good for drag reduction, namely, the fluid injected from the semi-closed space can reduce the distortion of the fluid pressure in the boundary layer, and the semi-closed space can accommodate horizontal flowing fluids, thus balancing the pressure difference only to the fluid injection.

In addition, the anti-corrosive engineering of pipes has long plagued scholars and engineers because corrosion brings about huge economic and energy losses each year. Surface treatment using chromium compounds has become an effective way to achieve an anti-corrosion effect in industrial processes, but has had a negative impact on the environment. It is therefore worth mentioning that superhydrophobic coatings have been widely used on a variety of engineering material surfaces to improve the corrosion resistance. New materials and fabrication methods used for preparing anti-corrosion coatings develop from the epoxy resin to the nano-composite coatings. However, more energy needs to be devoted to the anti-corrosion effect and self-healing function of a surface with micro/nano-structure damage.

Numerical simulation methods have been used to study the turbulent flow characteristics in superhydrophobic circular tubes. At different Reynolds numbers, different resistance characteristics are exhibited in a superhydrophobic circular tube [71]. The elbow is an integral part of the piping system, in which the erosion wear rate is 50-times higher than that of a straight pipe because of the thinning of the perforation. In this regard, Sun [72] designed biomimetic elbows based on shell ribs, and through numerical simulations, found that the low-velocity swirl area between the ribs acts as a buffer, lowering the impact velocity of the particles. At the same time, the change in the flow field caused by the ribs reduces the tendency of the particles to move toward the outside of the elbow, thereby reducing the chance of a collision of the particles with the wall surface. A bionic non-smooth interface has many broad application prospects in terms of pipeline drag reduction, although under different conditions such as the internal transport of multiphase media, the combination of a corrosion coating and biomimetic drag reduction interface are also extremely important regarding the lifetime prediction.

A biomimetic surface can improve the efficiency of the oil-water separation and the transportation dragreduction technology to a certain extent. However, a method to allow a biomimetic surface to operate stably for a long period of time and be prepared at a large-scale and low cost, and to allow the corresponding bionic surface to be reasonably selected according to the corresponding working conditions, is needed to ensure satisfactory results in practical engineering applications.

\section{Application in ocean and polar develop- ment}

The marine industries have become an important pillar in global economic development. An offshore platform is an important aspect in the development of oil and gas resources, and marine transportation has become an emerging force for the transfer resources. At this stage, all offshore oil and gas fields that have been put into use or are ready for development around the world are still dominated by shallow seas, and as the level of oil exploration increases, industry is gradually moving toward the deep sea. However, the influence of seawater resistance and marine corrosion causes large-scale damage and scrapping of various facilities and industrial equipment, resulting in significant energy consumption and economic losses. It is therefore becoming increasingly important to reduce the seawater resistance and control the corrosion damage of the equipment.

Similar to the oil/gas storage and transportation applications mentioned in the previous section, most friction surfaces have solid-liquid contact. Therefore, 
biomimetic surface technology has been successfully applied to reduce the resistance and corrosion in ocean waters. The preparation method $[73,74]$ and evaluation $[75,76]$ of a super-hydrophobic surface with an anti-corrosion performance have become popular research areas [77].

\subsection{Drag reduction of riser}

The riser system is the only channel that connects the blow-out preventer (BOP) and offshore drilling platform, and its length has continued to increase with the development of deep-sea exploitation. Correspondingly, the area acting on the surface of the riser also increases when the ocean current flows through the riser. In addition, vortex-induced vibrations caused by the flow resistance and lift force under such a large length have an increasing impact on the safety and reliability of the riser. Thus, the resulting tension has also placed higher demand on the performance of the tensioner and the strength of the riser joint. Through numerical simulations and an experimental analysis, it has been concluded that the biomimetic surface displays a better resistance to a drag reduction than a smooth surface. In trough and pit type surface models, the drag and lift coefficients have decreased by $16 \%$ and $6 \%$, respectively [78]. In addition, the resistance also shows a decreasing tendency prior to the increase in the depth of the bionic unit. Moreover, the application of a biomimetic surface structure applied in the drag-reduction technology of the riser has also provided another idea for the stable placement of large-scale subsea equipment such as subsea pipelines.

\subsection{Ocean transportation}

In recent years, marine oil ship, liquefied natural gas (LNG) transport ships, and many other types of oil ships have been undertaking the major task of China's offshore oil transportation. However, the enormous frictional resistance of the hull that occurs under contact with seawater is a problem [79]. A "green ship" with features such as renewable energy, biomimetic drag reduction, and wear-resistant coating has been seen as a potential solution to the problems facing the shipping industry [80]. Therefore, numerous studies have been conducted on biomimetic drag reduction and have achieved promising results. There are currently three types of biomimetic drag reduction technologies available: mimetic shark surface grooves, external jets, and a biomimetic superhydrophobic surface.

Global studies on the surface groove technology of a mimetic shark started earlier and have already been applied to an aircraft surface [81]. However, such research began to be carried out later in China. Wang [82] studied the drag reduction characteristics of four types of trench plates and found that the maximum local drag reduction of the trench plates can reach $13 \%-26 \%$. A preliminary discussion on the relationship between low-velocity strips and drag reduction properties was also provided, and it was found that the trench plates demonstrate a good drag reduction when their dimensionless height and spacing are 15-18 [83]. In another study, Cheng et al. [84] designed a secondary imitation shark trench surface and compared the flow field analysis data of the surface between the original V-groove and the secondary trench using the RNG $k-\varepsilon$ turbulence model. Moreover, the effects of the scale orientation on the performance of shark-skin-like surfaces have also been studied [85]. It is worth noting that the prepared surface can more effectively inhibit the turbulent flow in the boundary layer, reduce the viscosity of the fluid flow, and achieve a better drag reduction effect. In addition, an underwater drag reduction using gas has also made it possible to reduce the viscous drag through interfacial slippage of the gas entrained in the micro-structure surface [86].

In terms of a biomimetic superhydrophobic drag reduction, a good laminar flow drag reduction effect requires both simultaneous hydrophobicity and an appropriate roughness [87]. It was found that a superhydrophobic surface has a significant influence on the flow field in the near wall region, and it was proposed that the size of the micro-topography has a key effect on the drag reduction effect of a superhydrophobic surface, that is, a superhydrophobic surface drag reduction increases with an increase in the groove width and decreases with an increase in the flow velocity [88]. Many biomimetic surface drag reduction methods have been developed or are currently under development. For the oil and gas fields, particularly in the area of shipping, a brief comparison of three applicable drag reduction methods is illustrated in Table 3. Considering the harsh high- 
Table 3 Comparison of different biomimetic drag reduction surfaces.

\begin{tabular}{lll}
\hline \multicolumn{1}{c}{ Type } & Bionic prototype & Drag reduction mechanism \\
\hline Micro groove & Shark & (a) Protruding height \\
(b) Secondary vortex & (c) Blocking lateral vortex & (d) Scales of structures \\
Superhydrophobic & Lotus leaf & (a) Wall slipping model \\
Flexible buffering & (b) Plastron effect model & (c) Superhydrophobic effect \\
& &
\end{tabular}

pressure and low-temperature environment of a seabed, Wang et al. [89] proposed applying a biomimetic surface in an underwater production system, particularly for the surfaces of subsea pipelines and manipulators, which not only provides technical support for the complete flow of a subsea pipeline, it also increases the service life of the equipment.

Compared with the original surface, a biomimetic surface displays a better drag reduction. In addition, some surfaces have been successfully applied to related fields. Although biomimetic surfaces have significant potential application, there remain many urgent problems to be solved, including the large-scale preparation of superhydrophobic surfaces and an improvement of the drag reduction mechanism. To improve the performance evaluation, more energy should be invested into theoretical research. Presently, the adoption of biomimetic drag reduction technology is relatively simple. Perhaps a combination of a variety of drag reduction technologies may achieve a synergistic drag reduction effect.

\subsection{Marine anti-fouling coatings}

Despite the rapid development in marine drag reduction technology, there remain significant obstacles to its practical engineering application. For example, a large number of marine fouling organisms will stick to the surface of the hull during a voyage, such as barnacles, mussels, and micro-environmental fouling organisms. Hull fouling not only directly increases the frictional resistance with water and the fuel consumption, it also aggravates a corrosion of the hull, resulting in significant economic losses [90].

Thus far, researchers have put forward many ideas regarding anti-fouling technologies, including physical anti-fouling, chemical anti-fouling, and biological anti-fouling approaches. Biomimetic surface coatings use bionics principles to achieve an anti-fouling effect by simulating the epidermis structure of marine organisms, including sharks, shells, dolphins, and sea lions. It was found that shark epidermis has a weak antifouling ability against adult mussels, but a certain inhibitory effect on the attachment of microscopic biological diatoms. Brennan's research group [91] at the University of Florida, USA, used an epoxy-etched body as a mold to prepare a PDMS elastomer material with a micro/nanostructure, and the results showed that a drag reduction of $85 \%$ is reached, of which anti-fouling plays an important role. Images of the biomimetic morphology are shown in Fig. 6. Antifouling test results showed that the surface morphology of the material reduces the surface energy, resulting in a reduction of the biological attachment. Chen et al. [92] compared the anti-fouling effect of imitation 


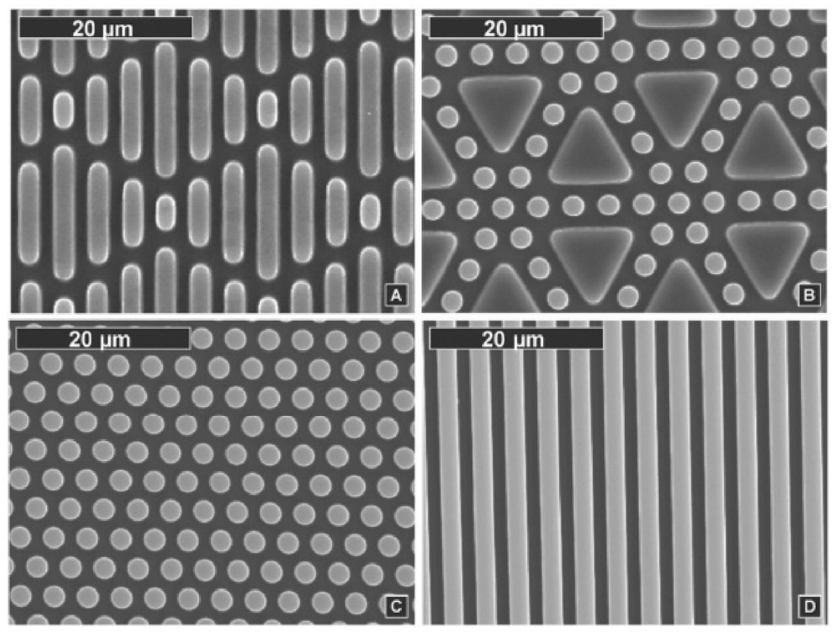

Fig. 6 Different biomimetic units applied on ship. Reproduced with permission from Ref. [91], (C) Taylor \& Francis 2007.

shark skin, taro leaf, and rose petal textures. Their experiments showed that all three imitation surfaces achieve a good hydrophobicity. The anti-fouling effect of the imitation shark skin with a laminated streamlined structure is clearly better than that of the other two groups; regular convex and pit texture models were therefore prepared. Interestingly, there is a positive correlation between the density of the pits and the anti-fouling capability. Bai et al. [90] selected seashells as bionic objects and took navicula in benthic diatoms as the research subject, establishing a model for the relationship between the surface characteristics of the shells and the concentration of navicula. From a physics perspective, they discussed the mechanism of the attachment of navicula spp. In addition, they established the relationship between the anti-marine biological adhesion and the surface microcosmic morphology of the shell surface and proposed the basic concept of the biological system for inhibiting marine fouling and biological adhesion. This provided a more comprehensive and powerful research method for studying the structure-activity relationship between biomimicry and fouling organisms, and the results obtained were closer to reality.

As shown in Fig. 7, the anti-fouling principle of surface flocking is mainly based on a physical barrier in which the villus layer becomes a substrate, which blocks the attachment of marine fouling organisms with different sizes. In addition, fluffs under the force of water accelerate their movement, which decrease the attachment stability of the organisms. Zhang et al. [93] adopted electrostatic flocking technology and used an acrylic resin as an adhesive. They applied a flocking using nylon (polyamide) and viscose fuzz on a glass sheet individually to simulate the preparation of the villus structure of sea lion epidermis and modified it to improve its hydrophobic properties. The effects of the flocking on the coating of three typical marine fouling organisms, namely, diatoms, mussels, and barnacles, were investigated. The results showed that a flocking surface has a significant inhibitory effect on the large fouling organisms, mussels and barnacles, and significantly reduces the number of attachments. However, there is no inhibitory effect

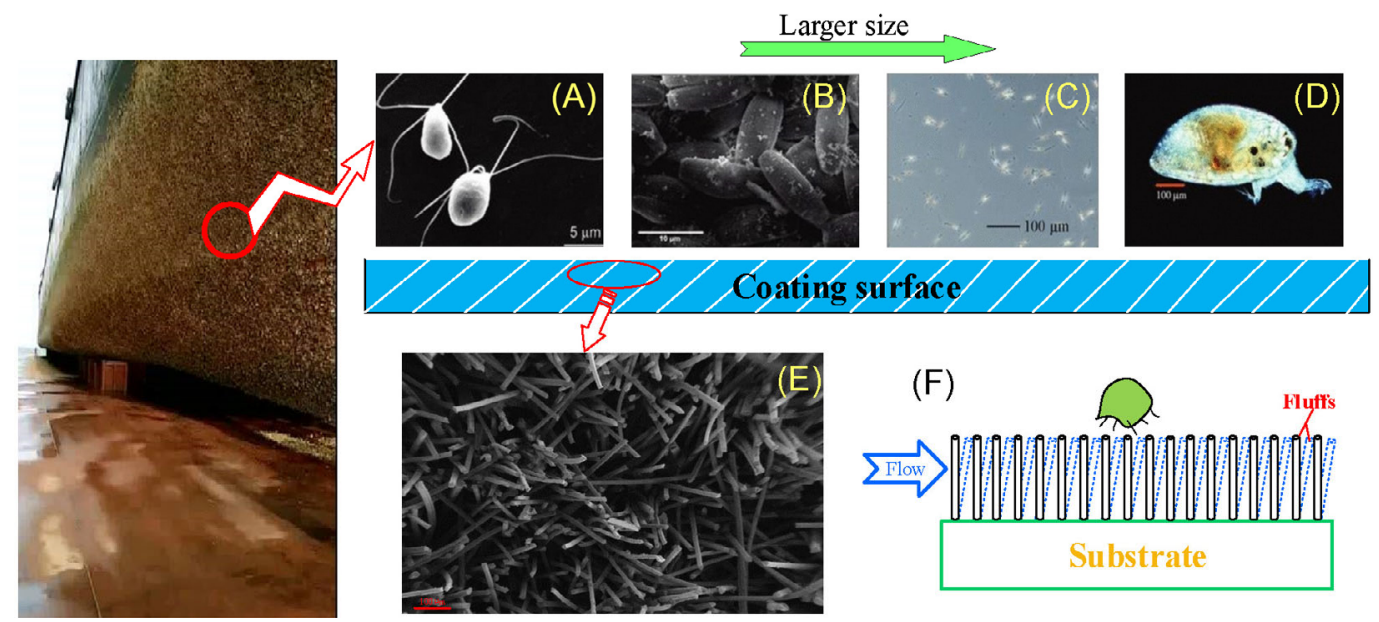

Fig. 7 Different volumes of micro-marine life: (A) ulva spores, (B) the diatom amphora, (C) the diatom nitzschia, and (D) the barnacle cyprid, at approximately 100-200 plush structures $/ \mathrm{mm}^{2}$; and anti-fouling mechanism: (E) microscopic morphology of fluffs, (F) schematic of anti-fouling mechanism. 
on the static attachment of the small-sized fouling bio-diatoms, although they are easily desorbed under water scouring. Thus, the removal rate was higher than on a surface without flocking. Nevertheless, the "attachment point" theory, which is dominated by the size of the surface micro-structure, can be affected by a complex marine environment and biological community, and cannot achieve complete anti-fouling. Therefore, research on biological fouling and antifouling mechanisms will contribute to the development of new technologies in this area.

Slippery liquid-infused porous surfaces (SLIPS) technology also facilitates the development of marine anti-fouling. The porous micro-structure of the underlying layer provides numerous small "cells" that help maintain a layer of lubricant that blocks contact between other liquids and the underlying solid while increasing the available surface area [94]. Wang et al. $[95,96]$ designed and fabricated SLIPS on an aluminum substrate and found that the surface was highly resistant to sulfate reducing bacteria (SRB) adhesion and the resulting microbial corrosion in static seawater. Epstein et al. [97] showed that SLIPS exhibits liquid repellency, smoothness, self-healing, and stability under high pressure, as well as a good optical transparency. Moreover, the silicone oil-infused sol-gel nanocomposite surfaces also exhibit outstanding long-term slippery stability and ultralow bacterial attachment even under extreme conditions [98]. Yong et al. [99] were the first to use a femtosecond laser to successfully fabricate a SLIPS surface, which was shown to be an excellent liquid-repellent and have a self-repair capability.

As countries come to increasingly value the protection of their ecological marine environments, the development of new types of green anti-fouling technologies is becoming a clear objective. In this regard, biomimetic anti-fouling technologies are a potential development direction. A comprehensive analysis of the structure and behavior of different biomimetic friction interfaces using multiple analysis methods at the micro/nanoscale is able to provide new ideas for the better protection of an ecological marine environment.

\subsection{Anti-icing coatings}

The Arctic region has recently become an active area for international oil companies owing to its vast oil reserves and gas exploration and development potential. However, nearly half of the basins in the Arctic region have yet to be explored with regard to oil and gas, and the region has shown the lowest level of global exploration and development. It is worth noting that severe weather such as extreme cold and hurricanes, as well as the effects of frozen tundra, are all factors hindering the development of polar oil and gas resources.

In the process of polar operations, the normal operation of large equipment such as electric power and transportation are often affected by ice, causing inconvenience or even accidents. The traditional method of anti-icing is mostly based on a melting method, which consumes large amounts of energy and is ineffective [100]. During the past few years, the main mechanisms of biomimetic anti-icing have been antifreezing (preventing water droplets from adhering to the surface and allowing direct removal before freezing) [101-105], the inhibition of ice nucleation (delaying the crystallization of water droplets, and thus extending the freezing time) [106, 107], and removal (reducing the adhesion force between the ice and surface, allowing the ice to easily to fall off) [108-112]. However, owing to a volume expansion that occurs during the icing, damaging, or riveting of micro/nanostructures, the surface coating loses its hydrophobicity, and the problem of an ultra-smooth porous coating is that it tends to fall off, which needs to be further solved [113]. However, for a fluorinated surface, only high fluorine contained compound (HFTES) contents (above 30wt.\%) exhibit anti-icing properties under freezing temperature [114]. Furthermore, the addition of photothermal materials [115], antifreeze proteins [116, 117], and commonly used anti-icing fluids [118] to the coating can also effectively delay the crystallization of water by lowering the freezing point or raising the surface temperature. Cheng et al. [119] prepared a magnetic superhydrophobic coating filled with air and a micro/ nanocomposite structure considering the hysteresis effect of $\mathrm{Fe}_{3} \mathrm{O}_{4}$ nanoparticles on the heat generation and photo-thermal effect. With the development of energy exploitation toward the polar regions, improving the performance of equipment under harsh conditions, such as low temperatures, will be a significant topic 
in the future. Nevertheless, to fabricate viable and durable anti-icing surfaces using superhydrophobic methods, further fundamental experimental and theoretical approaches are still necessary to investigate the effects of the wettability, surface roughness, surface morphology, and environmental conditions on the anti-icing performance [120].

A biomimetic surface with a good drag reduction or anti-fouling effect is a topic of research. However, differing from oil/gas storage and transportation, the application of a biomimetic marine surface needs to focus on the marine environment and biological resource protection. Therefore, a new environmentally material or coating [121] will be the focus of research in the near future.

\section{Conclusions and perspectives}

From the perspective of oil and gas industry development, the application of biomimetic surfaces can penetrate almost all aspects of the industrial chain, as shown in Fig. 8. In the current stage, the biomimetic friction interface has achieved certain research results in the field of oil and gas. Moreover, some of the results have even been tested and applied in the field. Nevertheless, the combination of a biomimetic friction interface and the petroleum industry still remains in the preliminary stage. Herein, we reviewed the efforts made toward biomimetic surfaces and superhydrophobic coatings integrated into the equipment and technology used in the oil and gas industry, which have had a significant influence on the preparation and characterization of biomimetic surfaces and their application. As can be seen from the development made in recent decades, the advantages of using biomimetic surface engineering to achieve an energy saving effect are becoming increasingly obvious, and new materials and methods are continuously being developed. However, there have been relatively few studies on an evaluation of the durability of biomimetic surface properties under actual conditions, particularly in the harsh, high-strength, heavy-load environments of the oil and gas industry. Until now, there have been no clear standards for an evaluation of the durability, whether in theory or through a simulation of the actual conditions (mechanical forces, abrasion, and corrosion, etc.), and such an evaluation

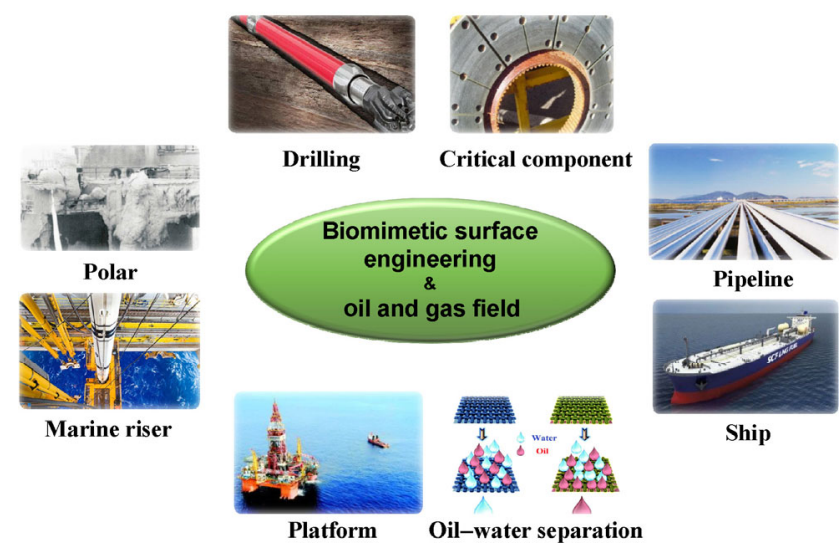

Fig. 8 Applications of biomimetic surface engineering in oil and gas industry.

remains a significant challenge for practical applications. Considering a complex environment, such biomimetic surfaces should have an optimized morphology and internal structure for the realization of multiple functions and persistence from the perspective of materials and processing. The solution to the problem may pave the way toward practical applications.

In the future, the biomimetic surfaces used in the oil field will mostly deal with the surfaces of the mechanical components. Biomimetic non-smooth functional surfaces should be applied to numerous equipment, pipelines, and platforms under harsh environments to improve the performance of the drag reduction, anti-wear, anti-corrosion, and anti-fouling, aiming to prolong the life of the equipment, improve the working efficiency, and reduce the safety risks. Again, to achieve significant improvements, new multi-functional surfaces (hydrophobic, hydrophilic, oleophobic, lipophilic, or super-amphiphobic) are required. In addition, a wide range of applications in the fields of industry, mining, petrochemical, metallurgy, machinery, and environmental protection exists.

Learning from nature is a consistent principle for the development of a biomimetic friction interface [122]. There are numerous mysterious surfaces that can drive us towards the development of novel surface technologies, which is one of the stages of biomimetic surface engineering research. We strongly believe that the application of biomimetic surface engineering in the oil and gas field has broad research prospects and 
values, which can greatly reduce the energy loss and protect the ecological environment [123, 124]. Practice has already proved that bionics can provide a more reliable, flexible, efficient, and economical technological system for the development and innovation of oil and gas fields [125]. To summarize, biomimetic surface engineering can cover most of the production needs of the oil and gas fields and provide innovative solutions and technical means for breakthroughs in key technical issues, thereby further promoting the technological progress of the petroleum industry and green development.

\section{Acknowledgements}

This work was supported by the National Natural Science Foundation of China (No. 51675534), and the Science Foundation of China University of Petroleum, Beijing (No. 2462017BJB06).

Open Access: This article is licensed under a Creative Commons Attribution 4.0 International Li-cense, which permits use, sharing, adaptation, distribution and reproduction in any medium or for-mat, as long as you give appropriate credit to the original author(s) and the source, provide a link to the Creative Commons licence, and indicate if changes were made.

The images or other third party material in this article are included in the article's Creative Commons licence, unless indicated otherwise in a credit line to the material. If material is not in-cluded in the article's Creative Commons licence and your intended use is not permitted by statutory regulation or exceeds the permitted use, you will need to obtain permission directly from the copyright holder.

To view a copy of this licence, visit http://creativecommons.org/licenses/by/4.0/.

\section{References}

[1] Zhang S W. Prospects for the development of biomimetic tribology. Lubric Eng 43(1): 1-2 (2018)

[2] Gao K, Li M, Dong B, Sun Y H, Sun Y, Liu J. Bionic coupling polycrystalline diamond composite bit. Pet Exp Dev 41(4): 533-537 (2014)

[3] Xu L, Sun Y H, Gao K. Efficient rock fragmentation mechanism analysis of impregnated diamond bionics bit. $J$ Jilin Univ (Earth Sci Ed) 38(6): 1015-1019 (2008)

[4] Gao K, Sun Y H, Ren L Q, Cao P L, Li W T, Fan H K. Design and analysis of ternary coupling bionic bits. J Bionic Eng S5: 53-59 (2008)

[5] Gao K, Sun Y H, Gao R F, Xu L, Wang C L, Li Y M. Application and prospect of bionic non-smooth theory in drilling engineering. Petr Exp Dev 36(4): 519-522, 541 (2009)

[6] Shi B R, Pei X H, Wei S B, Li T, Li Y L, Shao T M. Application of bionic non-smooth theory in solid expandable tubular technology. Appl Mech Mater 461: 476-481 (2014)

[7] Xuan Y, Jiang G C, Li Y Y, Geng H N, Wang J S. A biomimetic drilling fluid for wellbore strengthening. Pet Exp Dev 40(4): 531-536 (2013)

[8] Zheng L H, Wan X H, Zhang H J, Chi L J, Peng K W. A novel multifunctional bionic fuzzy-ball drilling fluid. $A d v$ Mater Res 236-238: 608-615 (2011)

[9] Shu X B, Meng Y F, Li G. Bionic technique-based treatment fluid for wellbore stability in drilling through shale formations. Pet Dril Tech 45(3): 15-20 (2017)

[10] Yan Z, Cong Q, Sun W W. The research of internal combustion engine piston skirts design methods. J Agric Mech Res 33(2): 188-192 (2011)

[11] Han Z W, Lü Y, Ma R F, Niu S C, Ren L Q. Dynamic performance of gear surface with bionic micro-morphology. J Beijing Univ Technol 37(6): 806-810 (2011)

[12] Cheng X J, Gao T Y, Ru S F, Cong Q. Wear performance of bionic dimpled-shape pistons of mud pump. Adv Mater Sci Eng 2017: 8256429 (2017).

[13] Mezghani S, Demirci I, Zahouani H, El Mansori M. The effect of groove texture patterns on piston-ring pack friction. Precis Eng 36(2): 210-217 (2012)

[14] Pettersson U, Jacobson S. Textured surfaces for improved lubrication at high pressure and low sliding speed of roller/ piston in hydraulic motors. Tribol Int 40(2): 355-359 (2007)

[15] Zhao Y, Ren L Q, Tong X, Zhou H, Chen L. Frictional wear and thermal fatigue behaviours of biomimetic coupling materials for brake drums. J Bionic Eng S5: 20-27 (2008)

[16] Zhou H, Zhang P, Sun N, Wang C T, Lin P Y, Ren L Q. Wear properties of compact graphite cast iron with bionic units processed by deep laser cladding WC. Appl Surf Sci 256(21): 6413-6419 (2010)

[17] Li H, Yu S R, Liu E Y, Zhao Y. Fabrication and characterization of bionic amphiphobic functional surface on X70 pipeline steel. Microsyst Technol 21(9): 2003-2010 (2015)

[18] Luo Y H, Zhang D Y, Liu Y F, Li Y Y, Ng E Y K. Chemical, mechanical and hydrodynamic properties research on composite drag reduction surface based on biological sharkskin 
morphology and mucus nanolong chain. $J$ Mech Med Biol 15(5): 1550084 (2015)

[19] Bixler G D, Bhushan B. Fluid drag reduction with shark-skin riblet inspired microstructured surfaces. Adv Funct Mater 23(36): 4507-4528 (2013)

[20] Zhang W B, Shi Z, Zhang F, Liu X, Jin J, Jiang L. Superhydrophobic and superoleophilic PVDF membranes for effective separation of water-in-oil emulsions with high flux. Adv Mater 25(14): 2071-2076 (2013)

[21] Wang B, Liang W X, Guo Z G, Liu W M. Biomimetic super-lyophobic and super-lyophilic materials applied for oil/water separation: A new strategy beyond nature. Chem Soc Rev 44(1): 336-361 (2015)

[22] Zang D M, Wu C X, Zhu R W, Zhang W, Yu X Q, Zhang Y F. Porous copper surfaces with improved superhydrophobicity under oil and their application in oil separation and capture from water. Chem Commun 49(75): 8410-8412 (2013)

[23] Wang N, Xiong D S, Deng Y L, Shi Y, Wang K. Mechanically robust superhydrophobic steel surface with anti-icing, UV-durability, and corrosion resistance properties. ACS Appl Mater Interfaces 7(11): 6260-6272 (2015)

[24] Zhang Z Z, Ge B, Men X H, Li Y. Mechanically durable, superhydrophobic coatings prepared by dual-layer method for anti-corrosion and self-cleaning. Colloids Surf A Physicochem Eng Asp 490: 182-188 (2016)

[25] Wang H M, Akid R. Encapsulated cerium nitrate inhibitors to provide high-performance anti-corrosion sol-gel coatings on mild steel. Corros Sci 50(4): 1142-1148 (2008)

[26] Brassard J D, Sarkar D K, Perron J, Audibert-Hayet A, Melot D. Nano-micro structured superhydrophobic zinc coating on steel for prevention of corrosion and ice adhesion. J Colloid Interface Sci 447: 240-247 (2015)

[27] Subramanyam S B, Rykaczewski K, Varanasi K K. Ice adhesion on lubricant-impregnated textured surfaces. Langmuir 29(44): 13414-13418 (2013)

[28] Zuo Z P, Liao R J, Guo C, Yuan Y, Zhao X T, Zhuang A Y, Zhang Y Y. Fabrication and anti-icing property of coral-like superhydrophobic aluminum surface. Appl Surf Sci 331: 132-139 (2015)

[29] Gu Y Q, Zhao G, Zheng J X, Li Z Y, Liu W B, Muhammad F K. Experimental and numerical investigation on drag reduction of non-smooth bionic jet surface. Ocean Eng 81: 50-57 (2014)

[30] Bai X Q, Zhang X, Yuan C Q. Numerical analysis of drag reduction performance of different shaped riblet surfaces. Mar Technol Soc J 50(1): 62-72 (2016)

[31] Fu Y F, Yuan C Q, Bai X Q, Li T. Study on drag reduction performance of antifouling ribbed surfaces. J Ship Prod Des 34(1): 32-41 (2018)

[32] Zhang B B, Li J R, Zhao X, Hu X H, Yang L H, Wang N, Li Y T, Hou B R. Biomimetic one step fabrication of manganese stearate superhydrophobic surface as an efficient barrier against marine corrosion and Chlorella vulgaris-induced biofouling. Chem Eng J 306: 441-451 (2016)

[33] Wang G, Zeng Z X, Wang H, Zhang L, Sun X D, He Y, Li L Y, Wu X D, Ren T H, Xue Q J. Low drag porous ship with superhydrophobic and superoleophilic surface for oil spills cleanup. ACS Appl Mater Interfaces 7(47): 26184-26194 (2015)

[34] Jiang J X, Zhang Q H, Zhan X L, Chen F Q. Renewable, biomass-derived, honeycomblike aerogel as a robust Oil Absorbent with two-way reusability. ACS Sustainable Chem Eng 5(11): 10307-10316 (2017)

[35] Zhang S W. Green tribology: Fundamentals and future development. Friction 1(2): 186-194 (2013)

[36] Liu H, Yang Q H, Pei X H, Zheng L C, Fu T, Shi B R, Wei S B, Chen L. Current status and development prospect of petroleum engineering bionics. Acta Petrol Sin 37(2): 273-279 (2016)

[37] Wang Z Z, Zhang Z H, Sun Y H, Gao K, Liang Y H, Li X J, Ren L Q. Wear behavior of bionic impregnated diamond bits. Tribol Int 94: 217-222 (2016)

[38] Wang Z Z, Gao K, Sun Y H, Zhang Z H, Zhang S Y, Liang Y H, Li X J, Ren L Q. Effects of bionic units in different scales on the wear behavior of bionic impregnated diamond bits. J Bionic Eng 13(4): 659-668 (2016)

[39] Sun Y H, He L K, Zhang C, Meng Q N, Liu B C, Gao K, Wen M, Zheng W T. Enhanced tensile strength and thermal conductivity in copper diamond composites with $\mathrm{B}_{4} \mathrm{C}$ coating. Sci Rep 7(1): 10727 (2017)

[40] Zhang P P, Li F H, Zhang X F, Zhang Z H, Tan C L, Ren L Q, Wang Y L, Ma W Y, Liu M. Effect of bionic unit shapes on solid particle erosion resistance of $\mathrm{ZrO}_{2}-7 \mathrm{wt} \% \mathrm{Y}_{2} \mathrm{O}_{3}$ thermal barrier coatings processed by laser. J Bionic Eng 15(3): 545-557 (2018)

[41] Chen Z W, Zhang H, Shen B, Yin G Q, Wang X F. A study on safe and dangerous drilling azimuths of horizontal well. Acta Petrol Sin 34(1): 164-168 (2013)

[42] Jiang G C, Xuan Y, Wang J S, Zhang H, Zhang Z H, Peng C Y. Study and application of bionic borehole wall strengthening agent. Drill Fluid Complet Fluid 31(3): 1-5 (2014)

[43] Tung S C, McMillan M L. Automotive tribology overview of current advances and challenges for the future. Tribol Int 37(7): 517-536 (2004) 
[44] Zhang J H, He Z P, Zhang G C, Ma Z Y, Gao H G, Ma L. Coupled thermal and mechanical load analysis in diesel engine piston. Transactions of CSICE 29(1): 78-83 (2011)

[45] Wu B, Xi P. Optimal design apply to orthogonal test in piston with bionic groove. In Proceedings of 2014 IEEE International Conference on Mechatronics and Automation, Tianjin, China, 2014: 805-809.

[46] Sun Y W, Ru S F, Cong Q. Wear-life experiment of drilling mud pump piston with dimple-shaped bionic surface. Acta Petrol Sin 38(2): 234-240 (2017)

[47] Song Q F, Liu Y B, Zhou H, Sun N, Ren L Q. Friction and wear behavior of bionic coupling brake drum processed by laser. J Jilin Univ (Eng Technol Ed) 37(5): 1069-1073 (2007)

[48] Wang S T, Liu K S, Yao X, Jiang L. Bioinspired surfaces with superwettability: New insight on theory, design, and applications. Chem Rev 115(16): 8230-8293 (2015)

[49] Wu Y X, Xu J Y. Oil and water separation technology. Adv Mech 45(1): 201506 (2015)

[50] Tao M M, Xue L X, Liu F, Jiang L. An intelligent superwetting PVDF membrane showing switchable transport performance for oil/water separation. Adv Mater 26(18): 2943-2948 (2014)

[51] Xiong Z, Lin H B, Zhong Y, Qin Y, Li T T and Liu F. Robust superhydrophilic polylactide (PLA) membranes with a $\mathrm{TiO}_{2}$ nano-particle inlaid surface for oil/water separation. J Mater Chem A 5(14): 6538-6545 (2017)

[52] Xue Z X, Wang S T, Lin L, Chen L, Liu M J, Feng L, Jiang L. A novel superhydrophilic and underwater superoleophobic hydrogel-coated mesh for oil/water separation. Adv Mater 23(37): 4270-4273 (2011)

[53] Zhang G F, Jiang J X, Zhang Q H, Gao F, Zhan X L, Chen F Q. Ultralow oil-fouling heterogeneous poly(ether sulfone) ultrafiltration membrane via blending with novel amphiphilic fluorinated gradient copolymers. Langmuir 32(5): 1380-1388 (2016)

[54] Zhang G F, Jiang J X, Zhang Q H, Zhan X L, Chen F Q. Amphiphilic poly(ether sulfone) membranes for oil/water separation: Effect of sequence structure of the modifier. AIChE J 63(2): 739-750 (2017)

[55] Jiang J X, Zhang Q H, Zhan X L, Chen F Q. A multifunctional gelatin-based aerogel with superior pollutants adsorption, oil/water separation and photocatalytic properties. Chem Eng J 358: 1539-1551 (2019)

[56] Fu Y C, Jin B Y, Zhang Q H, Zhan X L, Chen F Q. pHinduced switchable superwettability of efficient antibacterial fabrics for durable selective oil/water separation. ACS Appl Mater Interfaces 9(35): 30161-30170 (2017)

[57] Kwon G, Kota A K, Li Y X, Sohani A, Mabry J M, Tuteja A. On-demand separation of oil-water mixtures. Adv Mater
24(27): 3666-3671 (2012)

[58] Kota A K, Kwon G, Choi W, Mabry J M, Tuteja A. Hygroresponsive membranes for effective oil-water separation. Nat Commun 3: 1025 (2012)

[59] Xue Z X, Cao Y Z, Liu N, Feng L, Jiang L. Special wettable materials for oil/water separation. J Mater Chem A 2(8): 2445-2460 (2014)

[60] Lee C H, Johnson N, Drelich J, Yap Y K. The performance of superhydrophobic and superoleophilic carbon nanotube meshes in water-oil filtration. Carbon 49(2): 669-676 (2011)

[61] Tian D L, Zhang X F, Wang X, Zhai J, Jiang L. Micro/ nanoscale hierarchical structured $\mathrm{ZnO}$ mesh film for separation of water and oil. Phys Chem Chem Phys 13(32): 1460614610 (2011)

[62] Kobayashi M, Terayama Y, Yamaguchi H, Terada M, Murakami D, Ishihara K, Takahara A. Wettability and antifouling behavior on the surfaces of superhydrophilic polymer brushes. Langmuir 28(18): 7212-7222 (2012)

[63] Zhang W B, Zhu Y Z, Liu X, Wang D, Li J Y, Jiang L, Jin J. Salt-induced fabrication of superhydrophilic and underwater superoleophobic PAA-g-PVDF membranes for effective separation of oil-in-water emulsions. Angew Chem Int Ed 53(3): 856-860 (2014)

[64] Guo Y B, Yang L, Wang D G. Preparation and hydrophobic behaviours of polystyrene composite coating. Surf Eng 32(2): 95-101 (2016)

[65] Cao C Y, Ge M Z, Huang J Y, Li S H, Deng S, Zhang S N, Chen Z, Zhang K Q, Al-Deyab S S, Lai Y. Robust fluorinefree superhydrophobic PDMS-ormosil@fabrics for highly effective self-cleaning and efficient oil-water separation. $J$ Mater Chem A 4(31): 12179-12187 (2016)

[66] Xu X, Zhou H, Liu J, Ji Y. Study and application of bionic self-cleaning drag reducing technology in fluid pipeline. Process Equip Pip 50(3): 74-77 (2013)

[67] Watanabe K, Udagawa H. Drag reduction of non-newtonian fluids in a circular pipe with a highly water-repellent wall. AIChE J 47(2): 256-262 (2001)

[68] Choi C H, Ulmanella U, Kim J, Ho C M, Kim C J. Effective slip and friction reduction in nanograted superhydrophobic microchannels. Phys Fluids 18(8): 087105 (2006)

[69] Luo Y H, Song W, Wang X D. Water repellent/wetting characteristics of various bio-inspired morphologies and fluid drag reduction testing research. Micron 82: 9-16 (2016)

[70] Luo Y H, Yuan L, Li J H, Wang J S. Boundary layer drag reduction research hypotheses derived from bio-inspired surface and recent advanced applications. Micron 79: 59-73 (2015)

[71] Lü T, Chen X L. Numerical simulation of drag reduction of 
circular pipe with superhydrophobic wall in turbulent flow. J Shanghai Jiaotong Univ 43(8): 1280-1283 (2009)

[72] Sun HZ. Research on anti-erosion performance and mechanism of a pipe bend with the bio-inspired internal surface. Master's thesis. Changchun (China): Jilin University, 2017.

[73] Peng C W, Chang K C, Weng C J, Lai M C, Hsu C H, Hsu S C, Hsu Y Y, Hung W I, Wei Y, Yeh J M. Nano-casting technique to prepare polyaniline surface with biomimetic superhydrophobic structures for anticorrosion application. Electrochim Acta 95: 192-199 (2013)

[74] Liu Y, Xue J Z, Luo D, Wang H Y, Gong X, Han Z W, Ren L Q. One-step fabrication of biomimetic superhydrophobic surface by electrodeposition on magnesium alloy and its corrosion inhibition. J Colloid Interface Sci 491: 313-320 (2017)

[75] She Z X, Li Q, Wang Z W, Li L Q, Chen F N, Zhou J C. Researching the fabrication of anticorrosion superhydrophobic surface on magnesium alloy and its mechanical stability and durability. Chem Eng J 228: 415-424 (2013)

[76] Zhu Y J, Sun F L, Qian H J, Wang H Y, Mu L W, Zhu J H. A biomimetic spherical cactus superhydrophobic coating with durable and multiple anti-corrosion effects. Chem Eng $J$ 338: 670-679 (2018)

[77] Mohamed A M A, Abdullah A M, Younan N A. Corrosion behavior of superhydrophobic surfaces: A review. Arab $J$ Chem 8(6): 749-765 (2015)

[78] Wang G R, Liao C J, Hu G, Zhong L, Zhang M. Numerical simulation analysis and the drag reduction performance investigation on circular cylinder with dimples at subcritical Reynolds number. J Mech Strength 39(5): 1119-1125 (2017)

[79] Mo M T, Zhao W J, Chen Z F, Zeng Z X, Wu X D, Xue Q J. Research status of marine drag reduction technologies. Tribology 35(4): 505-515 (2015)

[80] Sun Y W, Yan X P, Yuan C Q, Bai X Q. Insight into tribological problems of green ship and corresponding research progresses. Friction 6(4): 472-483 (2018)

[81] Fu Y F, Yuan C Q and Bai X Q. Marine drag reduction of shark skin inspired riblet surfaces. Biosurf Biotribol 3(1): 11-24 (2017)

[82] Wang J J. Reviews and prospects in turbulent drag reduction over riblets surface. J Beijing Univ Aeron Astron 24(1): 31-33 (1998)

[83] Wang J J, Chen G. Experimental studies on the near wall turbulent coherent structures over riblets surfaces. Acta Aeron Astron Sin 22(5): 400-405 (2001)

[84] Cheng P P, Jiang C G, Wu C W. Numerical simulation of drag reduction characteristics in bionic secondary micro-grooved surface. China Sci 9(8): 940-943 (2014)
[85] Dai W, Alkahtani M, Hemmer P R, Liang H. Drag-reduction of 3D printed shark-skin-like surfaces. Friction, in press, DOI 10.1007/s40544-018-0246-2.

[86] Wang J D, Wang B, Chen D R. Underwater drag reduction by gas. Friction 2(4): 295-309 (2014)

[87] Yu Y S, Wei Q D. Experimental Study on Physical mechanism of drag reduction of hydrophobic materials in laminar flow. Chin Phys Lett 23(6): 1634-1637 (2006)

[88] Huang Q G, Pan G, Song B W, Liu Z Y, Hu H B. Numerical simulation of superhydrophobic surface's flow field characteristic and drag reduction rule. J Ship Mech 18(1-2): 1-11 (2014)

[89] Wang Y Y, Zhao Y, Zheng W, Duan M L, Chen H R, Du Y. Beyond self-cleaning: Next generation smart nanoscale manipulators and prospects for subsea production system. J Nanosci Nanotechnol 17(12): 8623-8639 (2017)

[90] Bai X Q, Yuan C Q, Yan X P, Liu X M. Research on green bionic ship antifouling techniques based on surface morphology of shell. J Wuhan Univ Technol 33(1): 75-78, 112 (2011)

[91] Schumacher J F, Carman M L, Estes T G, Feinberg A W, Wilson L H, Callow M E, Callow J A, Finlay J A, Brennan A B. Engineered antifouling microtopographies-Effect of feature size, geometry, and roughness on settlement of zoospores of the green alga Ulva. Biofouling 23(1): 55-62 (2007)

[92] Chen Z F, Zhao W J, Mo M T, Zhou C X, Liu G, Zeng Z X, Wu X D, Xue Q J. Architecture of modified silica resin coatings with various micro/nano patterns for fouling resistance: Microstructure and antifouling performance. $R S C A d v$ 5(118): 97862-97873 (2015)

[93] Zhang S Y, Zheng J Y, Fu Y B. Principle and research progress of surface flocking as marine antifouling technology. Paint Coat Ind 42(12): 72-76 (2012)

[94] Xiao L L, Li J S, Mieszkin S, et al. Slippery liquid-infused porous surfaces showing marine antibiofouling properties. ACS Appl Mater Interfaces 5(20): 10074-10080 (2013)

[95] Wang P, Lu Z, Zhang D. Slippery liquid-infused porous surfaces fabricated on aluminum as a barrier to corrosion induced by sulfate reducing bacteria. Corros Sci 93: 159-166 (2015)

[96] Wang P, Zhang D, Lu Z, Sun S M. Fabrication of slippery lubricant-infused porous surface for inhibition of microbially influenced corrosion. ACS Appl Mater Interfaces 8(2): 1120-1127 (2016)

[97] Epstein A K, Wong T S, Belisle R A, Boggsa E M, Aizenberg J. Liquid-infused structured surfaces with exceptional antibiofouling performance. Proc Natl Acad Sci USA 109(33): 13182-13187 (2012) 
[98] Wei C Q, Zhang G F, Zhang Q H, Zhan X L, Chen F Q. Silicone oil-infused slippery surfaces based on sol-gel process-induced nanocomposite coatings: A facile approach to highly stable bioinspired surface for biofouling resistance. ACS Appl Mater Interfaces 8(50): 34810-34819 (2016)

[99] Yong J L, Chen F, Yang Q, Fang Y, Huo J L, Zhang J Z and Hou X. Nepenthes inspired design of self-repairing omniphobic slippery liquid infused porous surface (SLIPS) by femtosecond laser direct writing. Adv Mater Interfaces 4(20): 1700552 (2017)

[100] Mishchenko L, Hatton B, Bahadur V, Taylor J A, Krupenkin T, Aizenberg J. Design of ice-free nanostructured surfaces based on repulsion of impacting water droplets. ACS Nano 4(12): 7699-7707 (2010)

[101] Cao L L, Jones A K, Sikka V K, Wu J Z, Gao D. Anti-icing superhydrophobic coatings. Langmuir 25(21): 12444-12448 (2009)

[102] Guo P, Zheng Y M, Wen M X, Song C, Lin Y C, Jiang L. Icephobic/anti-icing properties of micro/nanostructured surfaces. Adv Mater 24(19): 2642-2648 (2012)

[103] Wang Y Y, Xue J, Wang Q J, Chen Q M, Ding J F. Verification of icephobic/anti-icing properties of a superhydrophobic surface. ACS Appl Mater Interfaces 5(8): 3370-3381 (2013)

[104] Wang L, Gong Q H, Zhan S H, Jiang L, Zheng Y M. Robust anti-icing performance of a flexible superhydrophobic surface. Adv Mater 28(35): 7729-7735 (2016)

[105] Ruan M, Li W, Wang B S, Deng B W, Ma F M, Yu Z L. Preparation and anti-icing behavior of superhydrophobic surfaces on aluminum alloy substrates. Langmuir 29(27): 8482-8491 (2013)

[106] Wilson P W, Lu W Z, Xu H J, Kim P, Kreder M J, Alvarenga J, Aizenberg J. Inhibition of ice nucleation by slippery liquid-infused porous surfaces (SLIPS). Phys Chem Chem Phys 15(2): 581-585 (2013)

[107] Shen Y Z, Tao J, Tao H J, Chen S L, Pan L, Wang T. Anti-icing potential of superhydrophobic Ti6Al4V surfaces: Ice nucleation and growth. Langmuir 31(39): 10799-10806 (2015)

[108] Kim P, Wong T S, Alvarenga J, Kreder M J, AdornoMartinez W E, Aizenberg J. Liquid-infused nanostructured surfaces with extreme anti-ice and anti-frost performance. ACS Nano 6(8): 6569-6577 (2012)

[109] Lv J Y, Song Y L, Jiang L, Wang J J. Bio-inspired strategies for anti-icing. ACS Nano 8(4): 3152-3169 (2014)

[110] Chen L Q, Geissler A, Bonaccurso E, Zhang K. Transparent slippery surfaces made with sustainable porous cellulose lauroyl ester films. ACS Appl Mater Interfaces 6(9): 6969-6976 (2014)
[111] Chen J, Dou R M, Cui D P, Zhang Q L, Zhang Y F, Xu F J, Zhou X, Wang J J, Song Y L, Jiang L. Robust prototypical anti-icing coatings with a self-lubricating liquid water layer between ice and substrate. ACS Appl Mater Interfaces 5(10): 4026-4030 (2013)

[112] Zhang J L, Gu C D, Tu J P. Robust slippery coating with superior corrosion resistance and anti-icing performance for AZ31B Mg alloy protection. ACS Appl Mater Interfaces 9(12): 11247-11257 (2017)

[113] He M, Li H L, Wang J J, Song Y L. Superhydrophobic surface at low surface temperature. Appl Phys Lett 98(9): 093118 (2011)

[114] Tang Y Q, Zhang Q H, Zhan X L, Chen F Q. Superhydrophobic and anti-icing properties at overcooled temperature of a fluorinated hybrid surface prepared via a sol-gel process. Soft Matter 11(22): 4540-4550 (2015)

[115] Yin X Y, Zhang Y, Wang D A, Liu Z L, Liu Y P, Pei X W, Yu $\mathrm{B}$, Zhou F. Integration of self-lubrication and near-infrared photothermogenesis for excellent anti-icing/deicing performance. Adv Funct Mater 25(27): 4237-4245 (2015)

[116] Esser-Kahn A P, Trang V, Francis M B. Incorporation of antifreeze proteins into polymer coatings using site-selective bioconjugation. J Am Chem Soc 132(38): 13264-13269 (2010)

[117] Davies P L. Ice-binding proteins: A remarkable diversity of structures for stopping and starting ice growth. Trends Biochem Sci 39(11): 548-555 (2014)

[118] Sun T L, Qing G Y. Biomimetic smart interface materials for biological applications. Adv Mater 23(12): H57-H77 (2011)

[119] Cheng T T, He R, Zhang Q H, Zhan X L, Chen F Q. Magnetic particle-based super-hydrophobic coatings with excellent anti-icing and thermoresponsive deicing performance. J Mater Chem A 3(43): 21637-21646 (2015)

[120] Kreder M J, Alvarenga J, Kim P, Aizenberg J. Design of anti-icing surfaces: Smooth, textured or slippery? Nat Rev Mater 1(1): 15003 (2016)

[121] Wang H D, Ma G Z, Xu B S, Yong Q S, He P F. Design and application of friction pair surface modification coating for remanufacturing. Friction 5(3): 351-360 (2017)

[122] Han Z W, Mu Z Z, Yin W, Li W, Niu S C, Zhang J Q, Ren L Q. Biomimetic multifunctional surfaces inspired from animals. Adv Colloid Interface Sci 234: 27-50 (2016)

[123] Stachowiak G W. How tribology has been helping us to advance and to survive. Friction 5(3): 233-247 (2017)

[124] Holmberg K, Erdemir A. Influence of tribology on global energy consumption, costs and emissions. Friction 5(3): 263-284 (2017)

[125] Zhang S W. Recent developments of green tribology. Surf Topogr Metrol Prop 4(2): 023004 (2016) 


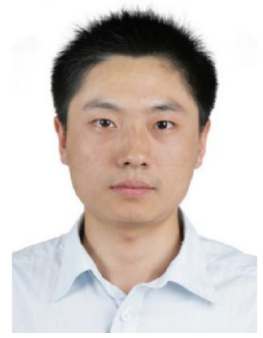

Yanbao GUO. Associate professor, obtained his bachelor degree and Ph.D. degree in 2005 and 2011 from China University of PetroleumBeijing. He worked with Prof. Tianmin Shao as a post doctor in Tsinghua University during 20112013. He worked as an associate professor since

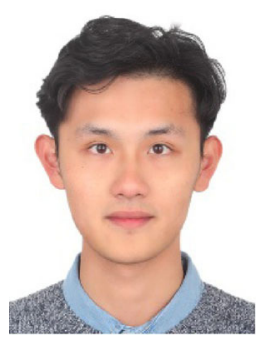

Zheng ZHANG. He received his bachelor degree in mechanical engineering in 2016 from China University of Petroleum, Qingdao, China. He is studying for his Ph.D.

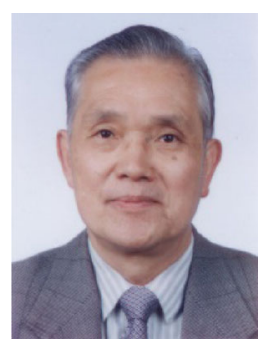

Siwei ZHANG. Professor of tribology and mechanical engineering of China University of Petroleum in Beijing. From 1982 to 1984, as a visiting professor, he studied in tribology of polymers at the Institute of Polymer Science, University of Akron, and then at the Tribology Laboratory, Department of Mechanical Engineering and Applied Mechanics, University of Michigan in USA. His professional interests include tribology and oilfield equipment. He mostly conducted and supervised in tribology of elastomers, friction materials, and tribological components of oilfield equipment. More
2013 at China University of Petroleum-Beijing. From September 2016 to September 2017, he was invited to Texas A\&M University in USA as a visiting scholar. His interested research areas include tribology and surface \& interface engineering in oil and gas industry. He has participated in many research projects and has published more than 20 papers on international journals during the past 5 years.

degree at the Mechanical and Transportation Engineering School of China University of Petroleum, Beijing. His research interests include tribology and failure analysis in oil and gas industry.

recently, he is interested in green tribology and theoretical systems of tribology.

He was the chairman of the Chinese Tribology Institution (CTI) in 2002-2006, and then the chairman of advisory board of CTI. Now, he is the vice-chairman of the supervisory committee of the State Key Laboratory of Solid Lubrication of Lanzhou Institute of Chemical Physics, Chinese Academy of Sciences, China, the associate editor-in-chief of the journal Lubrication Engineering (in Chinese). Also, he is the member of international advisory editorial board of journal Petroleum Science (English edition). In 2009, he received the Brilliant Contribution Award in tribology of CTI. 